\title{
DECREASING HALF-LIFE OF DIELDRIN IN EGG YOLK FOLLOWING A SINGLE ORAL ADMINISTRATION OF ALDRIN TO LAYING HENS
}

\author{
N. FURUSAWA ${ }^{*}$ \\ Faculty of Human Life Science, Osaka City University, Osaka 558-8585, Japan
}

(Received May 2, 2001; accepted September 5, 2001)

\begin{abstract}
Laying hens were treated orally with a single dose of aldrin (AD) $1 \mathrm{mg} / \mathrm{kg}$ body weight. Concentrations $(\mu \mathrm{g} / \mathrm{g})$ of $\mathrm{AD}$ or its epoxide (= dieldrin, $\mathrm{DD})$ in the yolk of eggs laid for 21 days after AD treatment were determined by normalphase high-performance liquid chromatography. The limits of determination were $0.02 \mu \mathrm{g} / \mathrm{g}$ for $\mathrm{AD}$ and $0.03 \mu \mathrm{g} / \mathrm{g}$ for $\mathrm{DD}$, respectively. After $\mathrm{AD}$ treatment, although the low levels of AD (mean $0.02-0.03 \mu \mathrm{g} / \mathrm{g}$ ) were observed only during a three-day period (from 4th to 6th days), DD (mean $0.15 \mu \mathrm{g} / \mathrm{g}$ ) was found already on the 2nd day, indicating that the epoxidation of AD to DD in the hen's body is rapid. The highest level of DD (mean $0.40 \mu \mathrm{g} / \mathrm{g}$ ) was detected on the 6th day, and then DD levels decreased slowly and were detected up to the 21 st day. In this decreasing phase, the half-life of DD in the yolk was estimated to be 25.6 days with a $95 \%$ confidence interval from 22.7 to 29.4 days.
\end{abstract}

Keywords: Aldrin, dieldrin, epoxidation, laying hens, egg yolk

Since aldrin (1,2,3,4,10,10-hexachloro-1,4,4a,5,8,8a-hexahydro-1,4:5,8dimethanonaphthalene, AD), a chlorinated cyclodiene insecticide, is extremely persistent in the environment. Its use has been restricted in the EU, USA and Japan. $\mathrm{AD}$ is metabolized (Fig. 1) in the liver to the stable epoxide, dieldrin (1,2,3,4,10,10-hexachloro-6,7-epoxy-1,4,4a,5,6,7,8,8a-octahydroendo-,exo1,4:5,8-dimethanonaphthalene, DD) by a cytochrome $\mathrm{P} 450$ dependent reaction (Wolff et al., 1979; Williams et al., 1982).

In poultry, $\mathrm{AD}$ and $\mathrm{DD}$, which are lipoid compounds, are persistent in the fat and can accumulate in eggs, especially in the yolk part, as a consequence of environmental contamination of the diet. The problem has often been demonstrated, and Naber (1977) and Kan (1978) reviewed this aspect.

Since AD and DD have received much attention as 'endocrine-disrupting chemicals' (Kavlock, 1996; EPA, 1997) and carcinogenic substances (IARC, 1987), it is feared that they exert some influence on the growth and egg laying of hens.

*E-mail: furusawa@life.osaka-cu.ac.jp; Fax: +81-6-6605-2864 


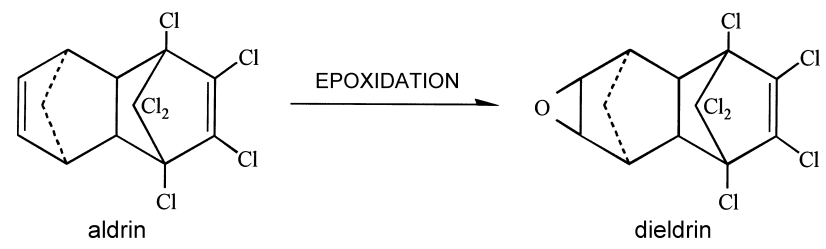

Fig. 1. Structures of aldrin and its epoxide (dieldrin)

Furusawa and Morita (2000) reported small accumulations of AD and DD in the eggs of laying hens exposed to these chemicals at present. This exposure can occur through contamination by the above-mentioned compounds. Knowledge of the kinetics of AD or DD in the egg yolk is essential to determine the duration of accumulation and toxicity of the compounds in the hens.

Gas chromatography with electron capture detection (GC-ECD) has been routinely used for analysing the trace residues of $\mathrm{AD}$ and $\mathrm{DD}$ simultaneously. High-performance liquid chromatography (HPLC) analysis is considered to be an analytically less sensitive method for determining AD and DD (Bushway, 1992; Grice et al., 1999), but this analysis could be used satisfactorily for pharmacokinetic studies in animals or for routine residue/contamination monitoring in foods, however at much higher ranges of concentrations.

The present study was designed to evaluate the following items for AD and for its epoxide, DD, in laying hens treated orally with $\mathrm{AD}: 1)$ transfer into egg yolk; 2) decreasing profiles in the yolk. This paper presents the kinetic data for $\mathrm{AD}$ and $\mathrm{DD}$ in the egg yolk.

\section{Materials and methods}

\section{Drug and animals}

$\mathrm{AD}$ and DD standards were obtained from Wako Pure Chem. Ltd. (Osaka, Japan). Nine laying Brown Leghorn hens (aged 12 months and weighing between 1.7 and $2.0 \mathrm{~kg}$ ) were randomly introduced into individual cages and given a drug-free basal layer diet and tap water ad libitum.

\section{Treatment}

Six hens were treated with a single oral dose, equivalent to AD $1 \mathrm{mg} / \mathrm{kg}$ body weight (b.w.): the test compound was administered to each hen via a capsule. The dose was absorbed on a small amount of the layer diet and applied orally in gelatin capsules. The other 3 hens were kept as untreated controls supplied only with a pure gelatin capsule. 
Of the 6 hens which were treated with $\mathrm{AD}, 3$ hens in good egg production (> 80\%) were selected. All of the eggs laid by these 3 hens were collected for 21 days. The albumen and the egg yolk of each egg were separated immediately. All the samples were stored in individual polyethylene bags and deep frozen $\left(-20^{\circ} \mathrm{C}\right)$ until analysis.

Analysis

The quantitative analyses for AD and DD in all samples were performed by an extraction procedure as described previously (Furusawa et al., 1999; Furusawa, 2001). That is, an accurately weighed amount (10 g) of sample was mixed sufficiently with a suitable amount of anhydrous sodium sulphate. Afterwards, the sample was homogenised in $20 \mathrm{ml}$ acetonitrile and $40 \mathrm{ml} n$-hexane (saturated with acetonitrile) using an autohomogeniser. After centrifugation at 3,500 rpm for $5 \mathrm{~min}$, the supernatant was poured though a separating funnel packed with anhydrous sodium sulphate. The dried hexane layer was collected and evaporated to dryness, and the lipid content was obtained (Furusawa et al., 1999).

The extracted lipid was dissolved in $1 \mathrm{ml}$ of hexane and was applied to an ISOLUTE-NH2 Solid-Phase Extraction column. AD and DD were eluted with $3 \mathrm{ml}$ of diethyl ether-hexane $(5: 95, \mathrm{v} / \mathrm{v})$ (flow rate, $<3 \mathrm{ml} / \mathrm{mm}$ ). The eluate was evaporated to dryness and the residue was dissolved in $1 \mathrm{ml}$ of the HPLC mobile phase. The solution was filtered though a $0.5 \mu \mathrm{m}$ filter unit. A $20 \mu$ portion was injected into the HPLC system.

For the HPLC system, JASCO HPLC (Model PU-980 pump and DG-98050 degasser) (Jasco Corp., Tokyo, Japan), equipped with SPD-M10Avp photodiode assay (PDA) detector at a wavelength of $210 \mathrm{~nm}$ (Shimadze, Kyoto, Japan), interfaced with Fujitsu FMV-5133D7 personal computer (Fujitsu, Tokyo, Japan) was used. The analytical column was a LiChrosorb ${ }^{\circledR} \mathrm{NH}_{2}(7 \mu \mathrm{m})$ column $(250 \times 4.6 \mathrm{~mm}$ i.d. $)$ equipped with a guard column $(5 \times 4.6 \mathrm{~mm}$ i.d. $)$ containing the same packing material. The following analytical characteristics were applied: mobile phase: heptane-hexane (97:3, v/v), flow rate: $1.0 \mathrm{ml} / \mathrm{ml}$ (Furusawa, 2001).

\section{Statistical analysis}

The significance of the differences between means were examined by Studentised Tukey's multiple comparisons test with one-way analysis of variance. Regression analyses on the relationships between natural logarithms (ln) of AD or $\mathrm{DD}$ concentrations in the samples and days after the $\mathrm{AD}$ administration were conducted for each hen. In this analysis, one regression line common to the 3 hens was derived for covariance analysis. The analysis was accomplished using SAS $^{\circledR}$ software (Ver. 6) packages (SAS Institute, Cary, NC, USA). 


\section{Results and discussion}

Figure 2 shows typical HPLC traces of blank, and residual AD and DD in extractable fats from egg yolk samples under the $\mathrm{AD} / \mathrm{DD}$ determination method used here. The resulting extract was free from spectral interference.

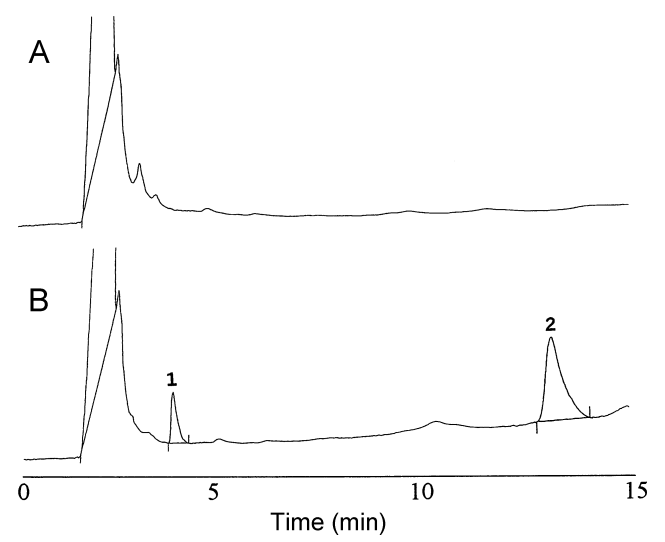

Fig. 2. HPLC chromatograms for extractable fats from egg yolk samples. A, blank egg yolk sample; B, an egg laid by the hen orally administered a single dose of aldrin (AD) $1 \mathrm{mg} / \mathrm{kg} \mathrm{b}$.w. For HPLC conditions see text. Peak 1 , AD $(0.1 \mu \mathrm{g} / \mathrm{g})$; Peak 2 , dieldrin $(0.5 \mu \mathrm{g} / \mathrm{g})$

Table 1 summarises the average recoveries of $\mathrm{AD}$ and $\mathrm{DD}$ from egg yolks at three different levels $(0.1,0.2$ and $0.4 \mu \mathrm{g} / \mathrm{g})$ considered to be satisfactory. The average recoveries were greater than $84 \%$ with coefficients of variation $(\mathrm{CV})$ between 3 and 7\%. The limits of determination (LOD) of AD and DD for egg yolk samples, which give clearly discernible peaks of $\mathrm{AD}$ and $\mathrm{DD}$ (signal-to-noise-ratio $>5$ ), were $0.02 \mu \mathrm{g} / \mathrm{g}$ for $\mathrm{AD}$ and $0.03 \mu \mathrm{g} / \mathrm{g}$ for $\mathrm{DD}$. These findings indicate that the present method has good precision and is accurate at the detected concentration ranges.

\section{Table 1}

Recoveries and limits of determination (LOD) for aldrin (AD)- and dieldrin (DD)fortified egg yolk

\begin{tabular}{lccc}
\hline & Spiked $(\mu \mathrm{g} / \mathrm{g})$ & $\mathrm{AD}$ & $\mathrm{DD}$ \\
\hline Recoveries $^{1}(\%):$ & 0.1 & $87(5)$ & $83(7)$ \\
& 0.2 & $85(4)$ & $84(5)$ \\
$\mathrm{LOD}(\mu \mathrm{g} / \mathrm{g})$ & 0.4 & $89(4)$ & $86(3)$ \\
& & 0.02 & 0.03
\end{tabular}

${ }^{1}$ Data are expressed as mean for five replicate analyses. Values in parentheses are coefficients of variation (\%) 
Table 2 presents the average daily feed intake and egg production during the experiment and the average body weight at one day before AD dosing and on the 21 st day after the treatment. There were no significant differences in the data for the treatment and the control groups. This suggests that the hens were healthy and laid normally during the experimental period, with no apparent ill effects attributable to the oral administration of a single dose of $A D$ at $1 \mathrm{mg} / \mathrm{kg} \mathrm{b.w}$.

Table 2

Daily feed intake, body weight and egg production in laying hens treated with a single oral dose of aldrin (AD) $(1 \mathrm{mg} / \mathrm{kg} \mathrm{b.w.)}$

\begin{tabular}{|c|c|c|}
\hline & \multicolumn{2}{|c|}{ Group } \\
\hline & Control & $\mathrm{AD}$ treatment \\
\hline Feed intake $^{1}$ (g/day) & $101 \pm 4$ & $105 \pm 2$ \\
\hline Body weight $^{1}(\mathrm{~kg})$ : & & \\
\hline before $^{2}$ & $1.82 \pm 0.05$ & $1.91 \pm 0.03$ \\
\hline after $^{3}$ & $1.81 \pm 0.04$ & $1.88 \pm 0.04$ \\
\hline Egg production ${ }^{4}(\%)$ & 86 & 90 \\
\hline
\end{tabular}

${ }^{1}$ Data are expressed as mean $\pm \mathrm{SD}\left[\mathrm{n}=21\right.$ (3 hens for 21 days)]; ${ }^{2}$ At one day before $\mathrm{AD}$ treatment; ${ }^{3}$ At the 21 st day after $\mathrm{AD}$ treatment; ${ }^{4} 100$. (the total of eggs laid by 3 hens during 21 days) $/ 3 \cdot 21$

Concentrations of $\mathrm{AD}$ and $\mathrm{DD}$ in the yolks of eggs laid after the $\mathrm{AD}$ dose are presented in Table 3. Low levels of AD were observed in the yolk during a three-day period (from the 4th to the 6th day) after AD treatment, and thereafter no $\mathrm{AD}$ was detected for another 15 days, indicating that $\mathrm{AD}$ in the hen's body was epoxidated instantaneously and its epoxide, DD, was transferred into the egg yolk. With the rapid epoxidation, a similar finding was obtained after intraperitoneal injection (Graham et al., 1991) in the blood of rats administered a $1 \mathrm{mg} / \mathrm{kg}$ dose. DD was already detected 2 days after AD dosing and its levels increased rapidly. The highest levels were observed on the 6th day after treatment, and then DD decreased slowly and was detected up to the 21 st day.

Table 4 presents the results of the regression and covariance analyses for the above 'decreasing phase' (6-21 days after AD treatment) of DD from the egg yolk. In all hens, significant linear regressions were observed between the natural logarithm of the DD content of egg yolk and the days after AD treatment $(\mathrm{P}<0.01)$. The following equation [1] common to all the hens was found fit to describe the decreasing phase. This equation was transformed into equation [2].

$$
\begin{aligned}
\ln y & =\ln a-0.0271 x \quad(\mathrm{r}=-0.9795, \mathrm{P}<0.01) \\
y & =a \cdot \mathrm{e}^{-0.0271 x} \quad
\end{aligned}
$$


Where $y$ is DD content $(\mu \mathrm{g} / \mathrm{g})$ in the egg yolk and $x$ and $a$ are the passed time (days) and the initial value of DD content in the decreasing phase, respectively. The coefficient of -0.0271 in equations [1] and [2] led a decreasing halflife of DD in the egg yolk to be $25.6(=\ln 2 / 0.0271)$ days with a $95 \%$ confidence interval from 22.7 to 29.4 days.

Table 3

Residues of aldrin (AD) and dieldrin (DD) in the yolk of eggs laid by laying hens treated with a single oral dose of $\mathrm{AD}(1 \mathrm{mg} / \mathrm{kg}$ b.w.)

\begin{tabular}{lcc}
\hline Days after treatment & \multicolumn{1}{c}{$\mathrm{AD}$} & $\mathrm{DD}$ \\
\hline 1 & $<0.02$ & $<0.03$ \\
2 & $<0.02$ & $0.15^{1}$ \\
3 & $<0.02$ & $0.18 \pm 0.02$ \\
4 & $0.02^{1}$ & $0.28^{1}$ \\
5 & $0.03 \pm 0.004$ & $0.33 \pm 0.05$ \\
6 & $0.02^{2}$ & $0.40 \pm 0.03$ \\
7 & $<0.02$ & $0.37 \pm 0.04$ \\
10 & $<0.02$ & $0.32 \pm 0.06$ \\
14 & $<0.02$ & $0.29 \pm 0.04$ \\
18 & $<0.02$ & $0.27 \pm 0.04$ \\
21 & $<0.02$ & $0.24 \pm 0.04$
\end{tabular}

Data are expressed as mean $(\mu \mathrm{g} / \mathrm{g}) \pm \mathrm{SD}(\mathrm{n}=3)$. The determining limits of $0.02 \mu \mathrm{g} / \mathrm{g}$ for $\mathrm{AD}$ and $0.03 \mu \mathrm{g} / \mathrm{g}$ for $\mathrm{DD}$, respectively, were established by the analytical method used here. ${ }^{1}$ Mean of two eggs laid on that day; no egg was laid by the $3 \mathrm{rd}$ hen. ${ }^{2}$ Mean of eggs laid by two hens; no $\mathrm{AD}$ was detected in the yolk of egg laid by the $3 \mathrm{rd}$ hen

No AD and DD were detected in the albumen because they are highly lipophilic compounds as described above. This should be due to the fact that the albumen contains a negligible amount of fat.

In egg yolk formation, the yolk protein precursor, vitellogenin, is transported via the blood from the liver to the ovary (Johnson, 1986). Since the yolk grows in the ovary for 7-11 days before ovulation, when the majority of yolk and lipids are deposited (Gilbert, 1971), the amounts of AD or DD in the yolk are a cumulative sum of the compound during the growth of the yolk. Thus, contents of DD in eggs depend largely on the physiology of egg formation. The egg has a separate compartment for the pharmacokinetics and it is independent of the hen's body. A definite disappearance in laying hens will depend on when the egg yolk becomes depleted of residues. 
Table 4

Covariance analysis for decreasing phase of dieldrin (DD) in the egg yolk after aldrin (AD) treatment

\begin{tabular}{lccccc}
\hline & Sum of squares $^{1}$ & Mean square $^{1}$ & $\mathrm{~b}^{2}$ & lna $^{2}$ & $\mathrm{r}$ \\
\hline Hen 1 & 0.0010 & & -0.0252 & -0.8302 & $-0.9955^{* *}$ \\
Hen 2 & 0.0130 & & -0.0291 & -1.0383 & $-0.9572^{* *}$ \\
Hen 3 & 0.0035 & & -0.0269 & -1.2354 & $-0.9857^{* *}$ \\
Within & 0.0175 & 0.0015 & & & \\
Reg. coef. & 0.0013 & 0.0006 & & & \\
Common & 0.0188 & 0.0013 & -0.0271 & & \\
Adj. means & 0.5215 & 0.2607 & & & \\
Total & 0.5402 & & & & \\
\hline
\end{tabular}

Test for the difference between regression coefficients $(b): F=0.43935^{-}(=0.0006 / 0.0015)$ Test for the difference between adjusted means (a): $\mathrm{F}=194.2830^{* *}(=0.2607 / 0.0013)$

${ }^{1}$ Deviations from regression; ${ }^{2} \ln y=\ln \mathrm{a}+\mathrm{b} x ; y=\mathrm{a} \cdot \mathrm{e}^{\mathrm{b} x} ; y$ is DD content $(\mu \mathrm{g} / \mathrm{g})$ in egg yolk and $x$ is the passed time (days) in the decreasing phase; r: Coefficient of correlation; ${ }^{* *}$ : Statistically significant $(\mathrm{P}<0.01) ;{ }^{-}$: Statistically not significant $(\mathrm{P}>0.05)$

The present study suggested that for the majority of $\mathrm{AD}$ administered orally to laying hens, the most important route of metabolism and elimination is rapid epoxidation in the liver. The decreasing pattern of epoxide, DD, in egg yolk could be described well by Equation [1] or [2] $(\mathrm{P}<0.01)$, although the study was carried out under conditions where the number of hens was limited $(n=3)$ and with short decreasing periods (from 6 to 21 days). This equation may be useful in judging the DD content in egg yolk.

\section{References}

Bushway, R. J. (1992): Food Analysis by HPLC. In: Nottet, L. M. L. (ed.) Marcel Decker, New York, p. 502.

EPA (Environmental Protection Agency) (1997): Special report on environmental endocrine disruption. In: EPA (ed.) An Effects Assessment and Analysis. U.S. Government Printing Office, Washington, D.C., p. 111.

Furusawa, N. (2001): Normal-phase high-performance liquid chromatographic determination and identification of aldrin, dieldrin, and DDTs in eggs. J. Chromatogr. Sci. 39, 183-187.

Furusawa, N. and Morita, Y. (2000): Polluting profiles of dieldrin and DDTs in laying hens of Osaka, Japan. J. Vet. Med. A 47, 511-515.

Furusawa, N., Ozaki, A., Nakamura, M., Morita, Y. and Okazaki, K. (1999): Simple and rapid extraction method of total egg lipids for determining organochlorine pesticides in the egg. J. Chromatogr. A 830, 473-476.

Gilbert, A. B. (1971): Yolk synthesis. In: Bell, D. J. and Freeman, B. M. (eds) Physiology and Biochemistry of the Domestic Fowl. Academic Press, London, pp. 1209-1233. 
Grice, I. D., Salzmann, M., Stiff, I. and Griffiths, L. R. (1999): Simultaneous determination of aldrin, dieldrin, endrin, heptachlor, and p,p'-DDT in medicinal plant extracts using a novel high performance liquid chromatography method. J. Liq. Chrom. \& R.T. 22, 2337-2344.

Graham, M. J., Williams, F. M. and Rawlins, M. D. (1991): Metabolism of aldrin to dieldrin by rat skin following topical application. Fd. Chem. Toxic. 29, 707-711.

IARC (The International Arctic Research Center) (1987): Overall evaluations of carcinogenicity. In: IARC (ed.) Monographs on the Evaluation of Carcinogenic Risks to Humans. University of Alaska, Fairbanks, Alaska, pp. 1-440.

Johnson, A. L. (1986): Reproduction in the female. In: Sturkie, P. D. (ed.) Avian Physiology. Springer-Verlag, New York, pp. 403-431.

Kan, C. A. (1978): Accumulation of organochlorine pesticides in poultry: A Review. J. Agric. Food Chem. 26, 1051-1055.

Kavlock, R. J. (1996): Research needs for the risk assessment of health and environmental effects of the U.S. EPA-sponsored Workshop. Environ. Health Perspect. 104 (Suppl. 4), 714-740.

Naber, E. C. (1977): The impact of contamination by organochlorine insecticides on poultry nutrition and feeding. Fed. Proc. 36, 1880-1887.

Williams, F. M., Woodhouse, K. W., Middleton, D. M., Wright, P., James, O. and Rawlins, M. D. (1982): Aldrin epoxidation kinetics in small samples of human liver. Biochem. Pharmacol. 31, 3701-3702.

Wolff, T., Deml, E. and Wanders, H. (1979): Aldrin epoxidation, a highly sensitive indicator specific for cytochrome P450 dependent mono oxygenase activities. Drug Metab. Dispos. 7, 301-305. 